\title{
Testing and simulation of a polypropylene-glass fibre reinforced woven composite on a wide range of strain-rates
}

\author{
A. Martin, R. Othman, and P. Rozycki \\ LUNAM Université, GeM Institute, École Centrale Nantes, 1 rue de la Noë, BP. 92101, 44321 Nantes \\ Cedex 3, France
}

\begin{abstract}
Medium costs composites materials are good candidates to develop lightweight and economical shock absorber for the next generation of cars. In this context we are interested in characterising and modelling of Twintex a long glass fiber reinforced polypropylene. Testing will be carried with a standard tensile rig and an original layout using a crossbow/Hopkinson rig. A special attention is made to compression behaviour identification, often neglected but critical for crash absorber behaviour. The model will be checked on the testing specimen and its validity will be discussed.
\end{abstract}

\section{Introduction}

We propose an experimental characterisation and a numerical model for the Twintex, a glass fiber-polypropylene woven composite showing good mechanical characteristics, availability and provided in a reasonable price range. Previous work on this material was done for the development of automotive absorber [1,2] and showed the potential of this composite. We will study the case for an equilibrated woven. To develop a crash absorber understanding compressive behaviour of a material is essential. We will use block specimen (Fig. 1) for compression following works [3-5] on microbuckling in compressed carbon epoxy materials. These layout where introduced to prove that compressive failure in AS4 epoxy composite is triggered by elastic buckling of fibers in the matrix. The sensitivity of material stiffness and plasticity to strain rate will be investigated following works on AS4 epoxy from Marguet [7] and works on thermoplastic by Schoßig [8]. A constitutive law is proposed based on a mesoscopic model $[7,9,11]$ and a comparison between tests and their simulation is exposed.

\section{Testing method}

Two kinds of samples are tested. A flat coupon with aluminium wedges is used for static tensile tests presented Fig. 2. A thick cube containing many layers is used for compression tests (Fig. 1). For $0^{\circ}$ traction specimens several geometry were tried but the flat coupon with aluminium wedges showed best strength and was the only one to break in gauge part far from grips. Flat coupons and cubes are large enough to contain a full representative element of the woven fabric. Flat coupons are $200 \times 25 \times 3 \mathrm{~mm}^{3}$ with a $100 \mathrm{~mm}$ long useful zone. They contains 6 ply and orientations are $\left[0^{\circ}\right]$ or $[ \pm 45]$. Cubes dimensions are $20 \mathrm{~mm}$ by side and contain 40 ply. A $100 \mathrm{kN}$ INSTRON test rig is used to process static experiments for both compression and tensile. It is equipped with auto-tightening grips for traction and two plates for compression. Dynamic crushing of cubes is carried out

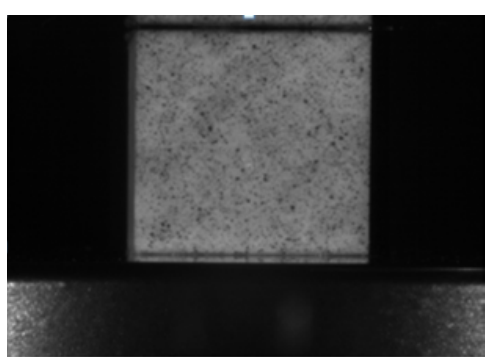

Fig. 1. Compression specimen between plates.

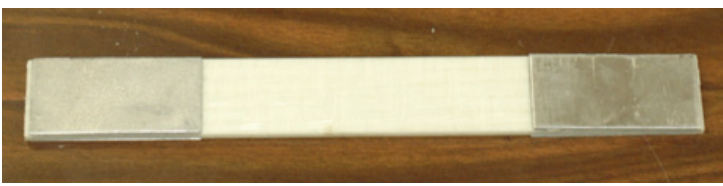

Fig. 2. Tensile specimen.

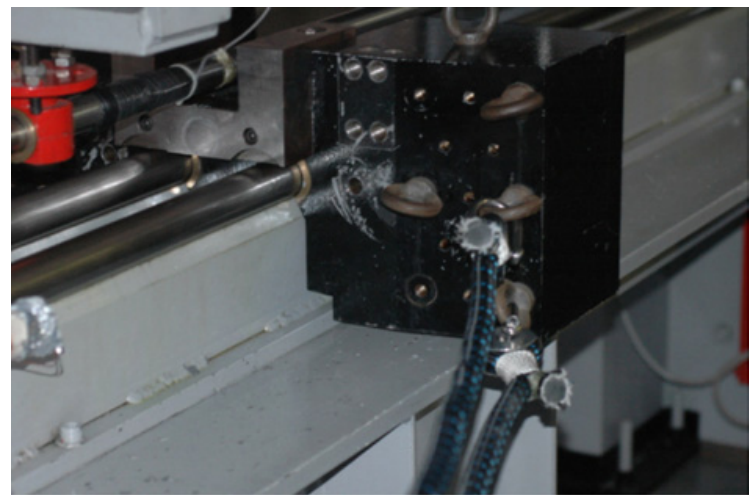

Fig. 3. Crossbow/Hopkinson impactor.

with a crossbow system depicted in Fig. 3. The experimental set-up is equipped with a high speed video camera: PHOTRON APX It allows us to following qualitatively the absorption mechanism for compression testing and data will be available for future work using correlation.

The quasi-static tensile and compression experiments are carried out at a strain rate equal to $0.001 / \mathrm{s}$. On the crossbow system two impact speeds are investigated: $4 \mathrm{~m} / \mathrm{s}$ 


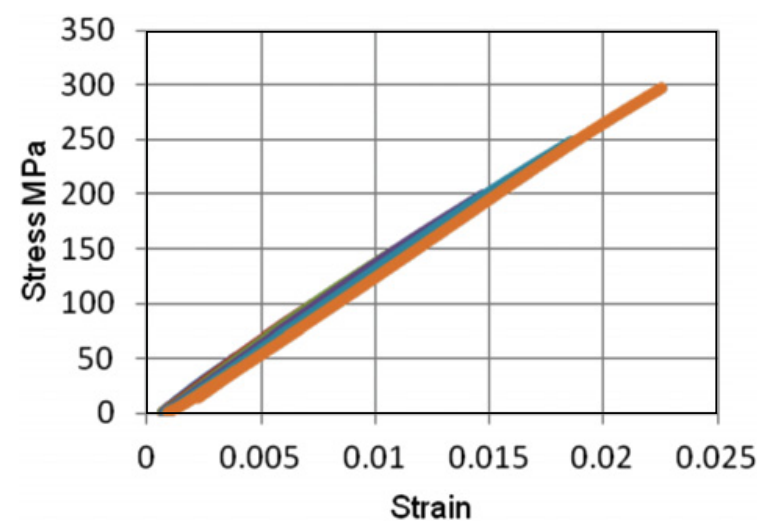

Fig. 4. Cycled quasi static tensile test.

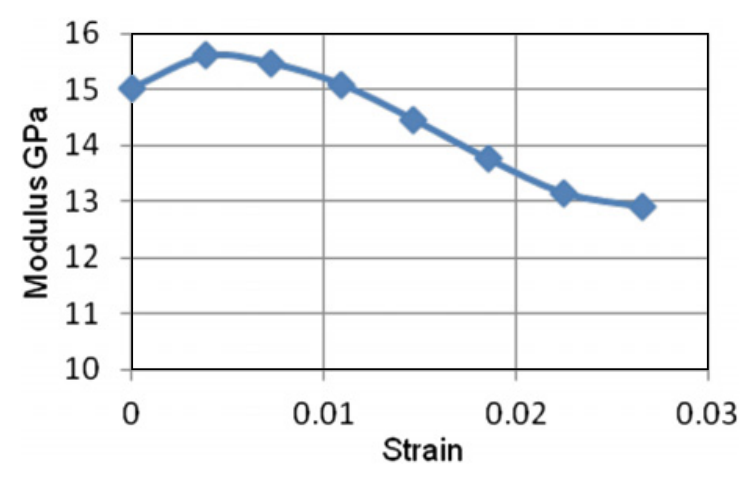

Fig. 5. Modulus evolution with strain $0^{\circ}$ specimen.

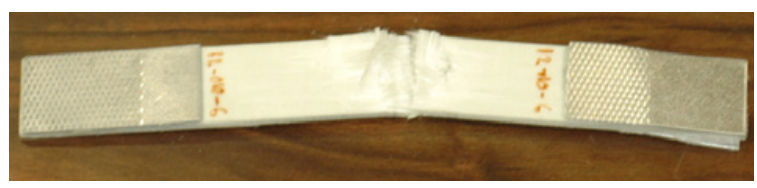

Fig. 6. $0^{\circ}$ Tensile specimen broken.

and $8 \mathrm{~m} / \mathrm{s}$ yielding strain rates of $200 / \mathrm{s}$ and $400 / \mathrm{s}$ respectively. At quasi-static strain rates, some specimens are loaded by cycle of solicitation-relaxation. This allows measuring plastic strain at zero stress and isolate damage $d$ on the next loading. With E actual Young modulus, Eo initial Young modulus damage $d$ is defined as:

$$
\mathrm{E}=\mathrm{Eo} \times(1-d)
$$

\section{Test results}

\subsection{Traction $0^{\circ}$}

Behaviour is almost elastic with brittle rupture (Fig. 4). We can observe a loss of modulus "damage" with cycles (Fig. 5). From an initial $15 \mathrm{GPa}$ modulus goes to $13 \mathrm{GPa}$ before a fragile breaking at $3.2 \%$. A specimen broken in the useful region is pictured Fig. 6.

\subsection{Traction $45^{\circ}$}

$\pm 45^{\circ}$ specimens show permanent plastic deformation after loading at no stress (Fig. 7 and 8), a sensible loss in modulus (Fig. 8) and an important hysteresis (Fig. 7).

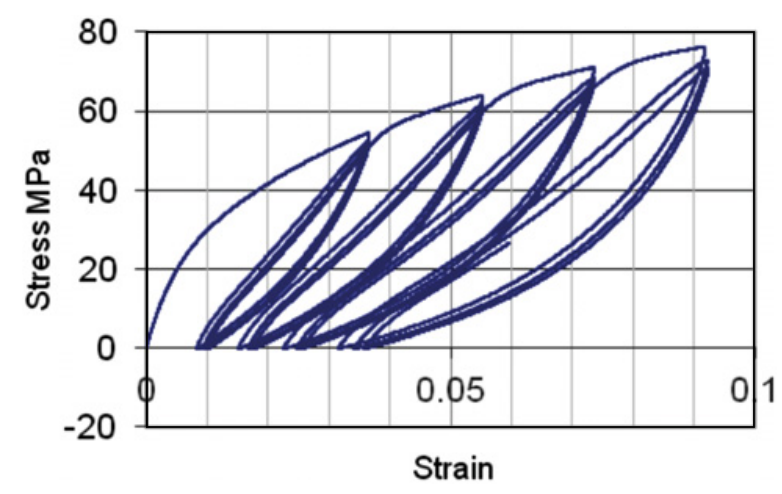

Fig. 7. Cycled quasi-static tensile test $\pm 45^{\circ}$.

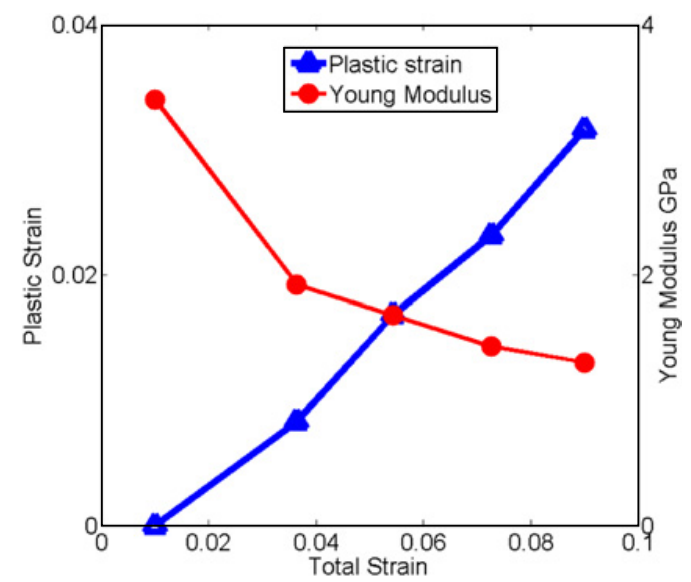

Fig. 8. Plastic strain and Young modulus evolution with total strain. \pm 45 specimen.

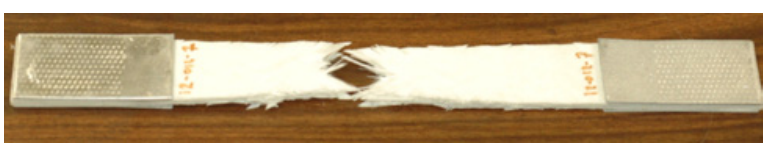

Fig. 9. $\pm 45^{\circ}$ Tensile specimen broken.

On the \pm 45 degree specimens non-linear effects are much more important. The modulus goes from $3.4 \mathrm{GPa}$ initially to $0 \mathrm{GPa}$ for $17 \%$ strain. Breaking occurs in a smooth sliding around $22 \%$ strain, Fig. 9.

\subsection{Compression $0^{\circ}$}

Quasi static cycled tests were conducted but showed no reduction in modulus between cycles. A kind of adaptation of specimen to metal plates pushing them occurred but the strain measure is in the 0.001 range and so will be neglected. Two kind of dynamic tests are presented. A first set of 3 specimens where impacted at $4 \mathrm{~m} / \mathrm{s}$ and failure did not occur. In a second time those where impacted and destroyed at $8 \mathrm{~m} / \mathrm{s}$. A second set was tested directly at $8 \mathrm{~m} / \mathrm{s}$. Those results are compared to a static test (Fig. 10). A low pass filter with a $35 \mathrm{kHz}$ cut is used to remove parasites.

Modulus in static compression is $50 \%$ lower than in traction and maximum stress see the same reduction (Fig. 11). Rising impact speed increase Young modulus but it does not reach static traction stiffness. A possible 


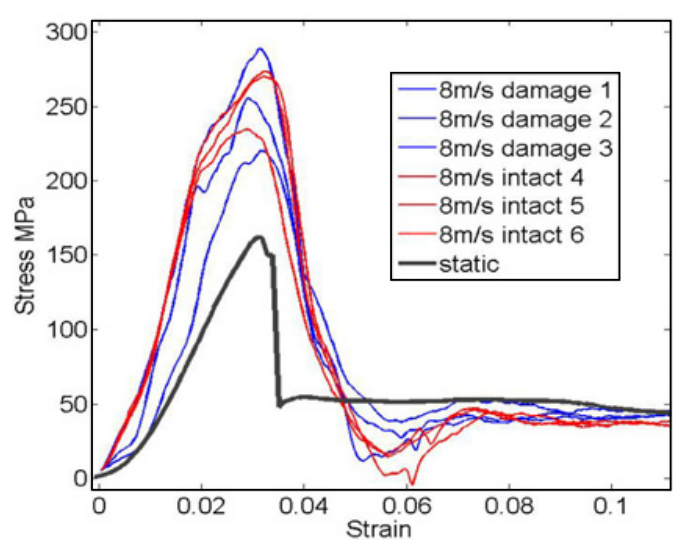

Fig. 10. Compression $0^{\circ}$ specimens results.

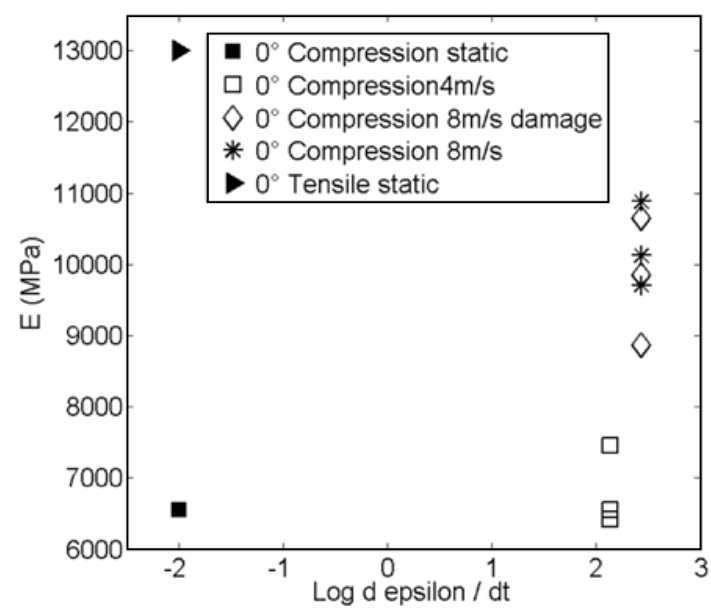

Fig. 11. $0^{\circ}$ Modulus evolution with strain rate.

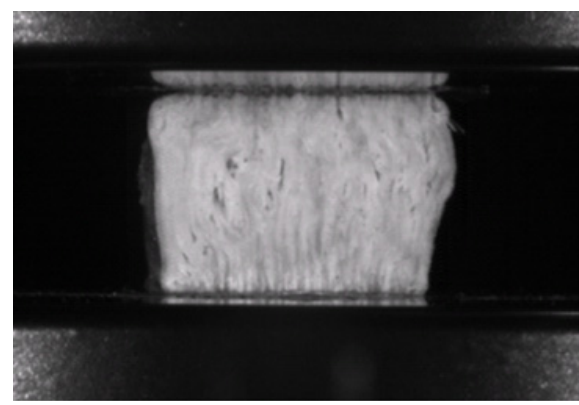

Fig. 12. Compression testing. Ply buckling.

interpretation is that ply buckles in compression as shown on Fig. 12 and so contribute less to the resistance of the composite structure. When speed raise inertia reduce lateral movement freedom and limits buckling so the qualities seen in traction on the material are recovered. Moreover high strain rate tensile testing shows the matrix has the ability to stiffen with strain rate reinforcing even more the anti buckling effect around plies. Each fiber can also buckle by itself and modify modulus/strength with speed sensitivity but we don't have any way to measure that for now.

Two out of three specimens being damaged before their $8 \mathrm{~m} / \mathrm{s}$ crush show no particular difference with intact

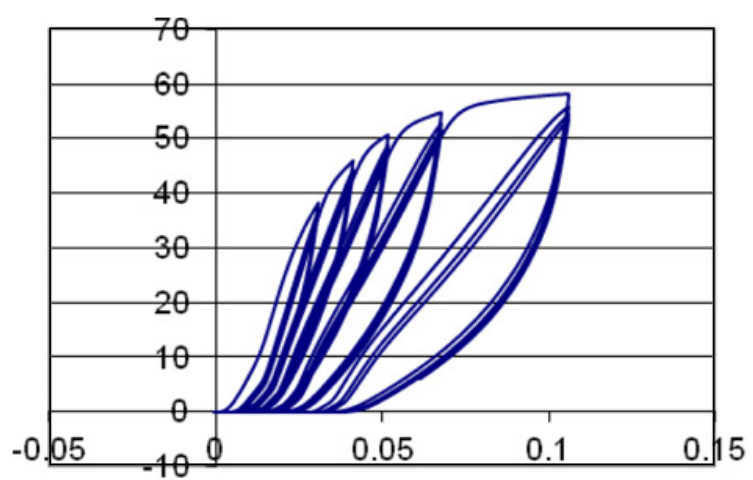

Fig. 13. Cyclic static compression.

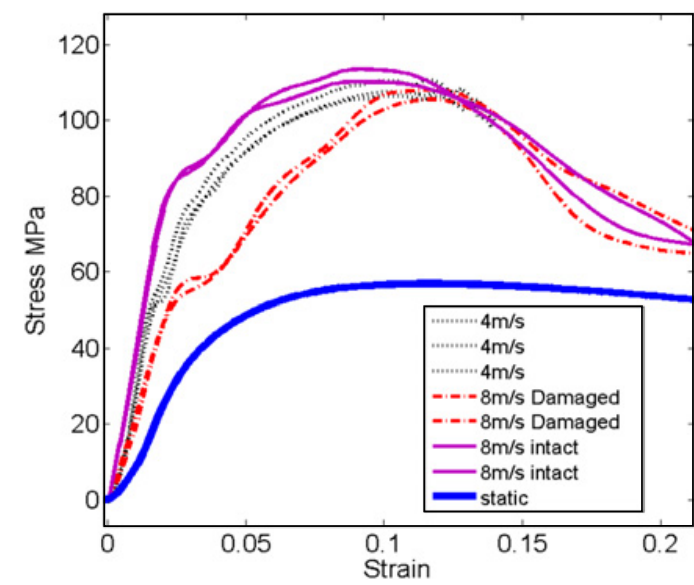

Fig. 14. Compression $\pm 45^{\circ}$ specimens results.

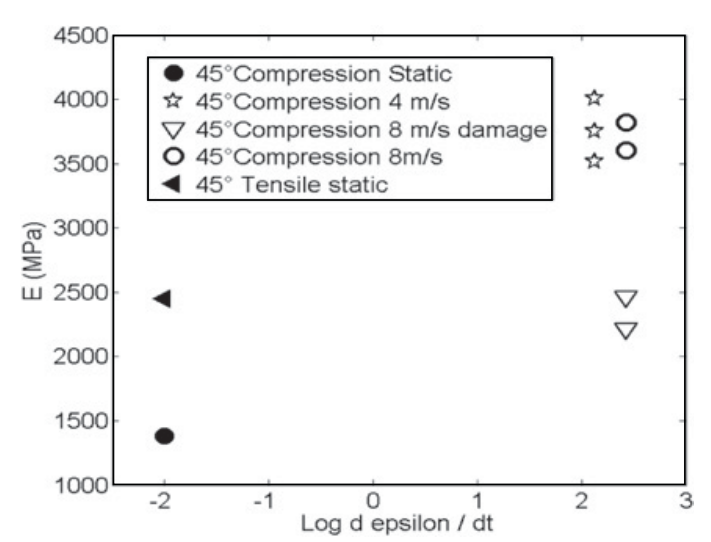

Fig. 15. $\pm 45^{\circ}$ Modulus evolution with strain rate.

specimen but one is softer. A pack of fibers may have been deteriorated by the first test.

\subsection{Compression $45^{\circ}$}

For $45^{\circ}$ specimen behaviour is comparable with traction tests but stress levels are $20 \%$ lower for a given strain (Fig. 13). Maximum stress is obtained at a smaller $13 \%$ strain (Fig. 14). Static modulus is $45 \%$ lower in compression compared to traction with $1.4 \mathrm{GPa}$ compared to 2.5 GPa (Fig. 15).

Young modulus for $\pm 45^{\circ}$ specimen is increasing with speed but the difference is much more important than $0^{\circ}$ 
specimen with a 2.7 factor. This time high speed modulus is $34 \%$ more important than traction modulus that means buckling lock is not a possible hypothesis for this effect. It can be noted too that $4 \mathrm{~m} / \mathrm{s}$ and $8 \mathrm{~m} / \mathrm{s}$ show very similar modulus. Our proposition to explain those evolutions is that the polypropylene matrix show a high sensitivity to strain rate and that hardening is already "capped" at $4 \mathrm{~m} / \mathrm{s}$ explaining the similar results between $4 \mathrm{~m} / \mathrm{s}$ and $8 \mathrm{~m} / \mathrm{s}$.

\subsection{Testing campaign conclusion}

The Twintex is a material showing a quasi-brittle behaviour when fiber orientation is $0^{\circ}$. However material properties are lower in compression but an impact speed raise can restore partially those properties. $45^{\circ}$ Specimen are much softer and stiffen quickly with strain rate. They present lower properties in compression too.

\section{Numerical model}

We are using an evolution of a mesoscopic model $[9,11]$ with explicit formulation developed previously inside our laboratory [7]. This model is based on a work on dynamic damage evolution in carbon epoxy composite. For a mesoscopic model two laws are defined, one for the ply and one for the interface. Directions reinforced by fiber are elastic with a damage factor. K11 and K22 are stiffness matrix factor for direction 1 and 2:

$$
\boldsymbol{K} 11=\frac{E 1 \times(1-d 1)}{1-v 12^{2}} \quad \boldsymbol{K} 22=\frac{E 2 \times(1-d 2)}{1-v 12^{2}}
$$

with Ei young modulus, di damage factor for direction $i$. v21 is the Poisson's coefficient.

Damage evolution energy Yi is computed for direction 1 and 2 with respective strain $\varepsilon$ ii:

$$
\boldsymbol{Y} 1=\frac{1}{2} \mathbf{E} \mathbf{1} \times \varepsilon \mathbf{1 1}^{2} \quad \boldsymbol{Y} 2=\frac{1}{2} \mathbf{E} \mathbf{2} \times \varepsilon \mathbf{2 2}^{2}
$$

A function defining damage evolution is defined:

$$
f(Y 1)=\frac{\sqrt{Y 1}-\sqrt{Y o 1}}{\sqrt{Y c 1}-\sqrt{Y o 1}}=d 1
$$

Yoi represent a minimum energy for initiating damage for direction i. Yci is the energy corresponding to full damage (1.0) for direction i.

This kind of model does not converge with mesh refining so we are using a model regularization by controlling damage evolution rate:

$$
\dot{d}_{l}=\frac{1}{\tau}\left(1-e^{-\alpha\langle f(Y i)-d i\rangle}\right)
$$

A Newton method is used to guarantee convergence between stress and damage at each time point. A comparable law is used for interface behaviour to describe delaminating but damage is shared with a common damage factor for opening and shear delaminating. A maximum damage is defined to delete the element past a specified damage.

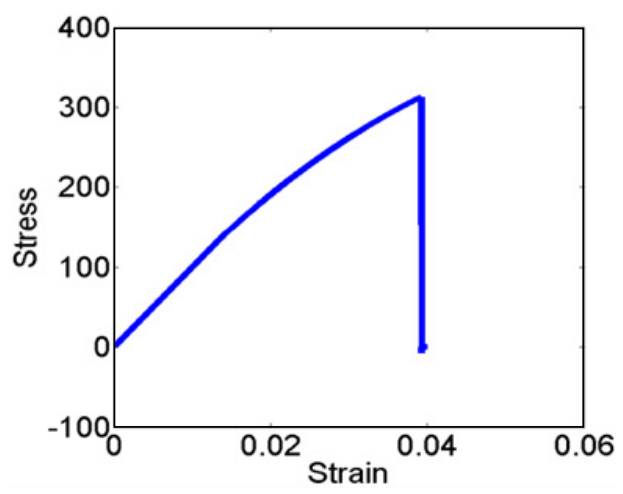

Fig. 16. $0 / 90^{\circ}$ Solicitation example. Damage only, 0.1 limit.

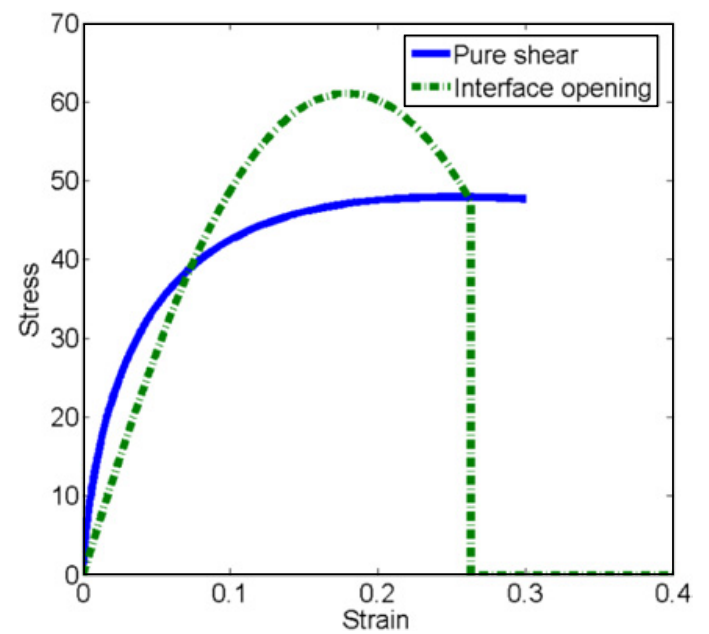

Fig. 17. Interface with pure damage 0.7 limit. Shear with damage/plastic behaviour.

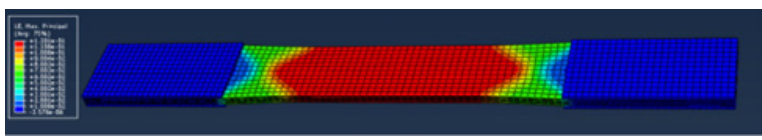

Fig. 18. Tensile model $45^{\circ}$.

For shear behaviour plasticity is taken into account with standard plasticity hardening and is time regularized too. Damage evolution is using a modified evolution formula:

$$
f(Y 12)=\frac{\log (Y 12)-\log (Y o 12)}{\log (Y c 12)-\log (Y o 12)}
$$

A set of variables has to be determined at each time step comprising stress, plastic strain, a plastic parameter and finally damage. A Newton method for multiple variables, return mapping algorithm [10], is used to find a valid set of variables within acceptable error. Figure 16, 17 and 18 show typical reaction of model at integration point:

Modulus, Yo, Yc and maximum damage can all be affected by strain rate with Johnson Cook type of formulation if needed following work from Johnson [11].

Ply elements material properties are identified with tensile tests results. Interface elements are identified with an invert method on compression testing simulation. A possible alternative would be to use a Double Cantilever Beam rig to identify interface coefficients. 


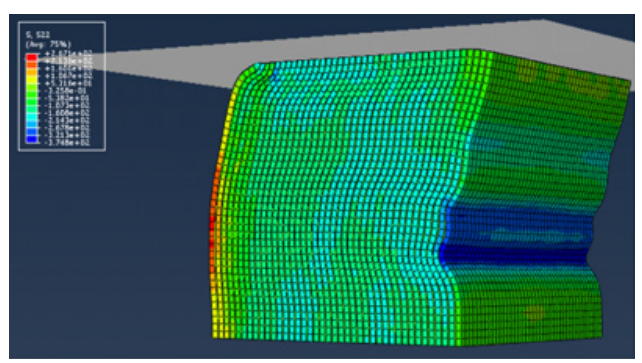

Fig. 19. Compression simulation.

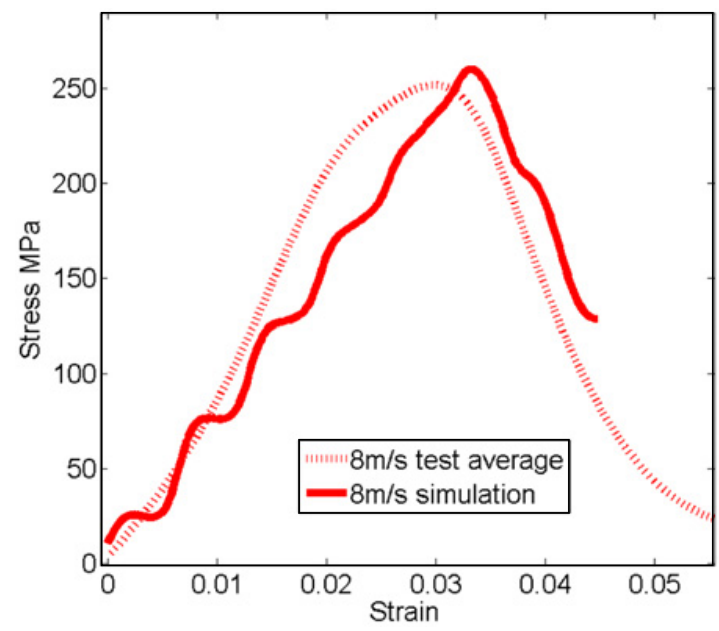

Fig. 20. Model results compression $0^{\circ} 8 \mathrm{~m} / \mathrm{s}$.

The objective is to present a model describing observed physics correctly but keeping a reasonable computational time cost. Material law is coded in FORTRAN and implemented in ABAQUS Explicit solver via VUMAT interface.

\section{Simulations results}

Both tensile and compression testing are presented.

\subsection{Traction simulation}

Reproducing the tensile test in the simulation is interesting compared to a simple model calculation at integration point because it takes into account structural modification in the specimen (Fig. 19).

The correlation with experiment is good. Aluminum wedges have been brought to the model to correctly represent boundaries, simpler conditions badly affect results. Chosen law is satisfying to represent tensile tests.

\subsection{Compression simulation}

Test rigs surfaces are represented by an analytical rigid plate. For the crossbow system a mass and an initial speed are added to plate properties. A general contact conditions is included.

Empirical observations from damaged specimens (Fig. 12, Fig. 24) and video show obtained failure mode with our model (Fig. 20) are comparable to reality.

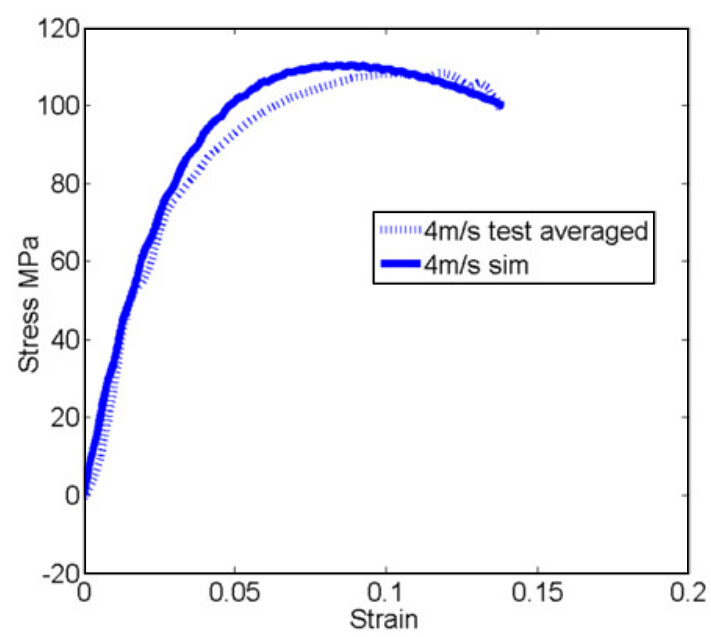

Fig. 21. Model results compression $45^{\circ} 4 \mathrm{~m} / \mathrm{s}$.

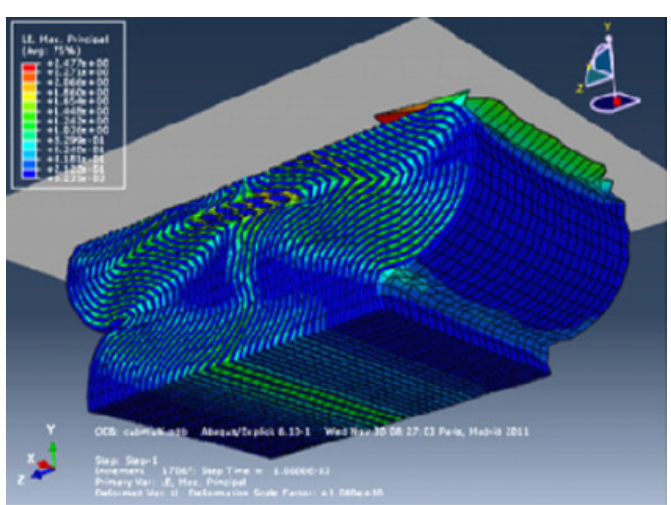

Fig. 22. Simple law $0^{\circ}$.

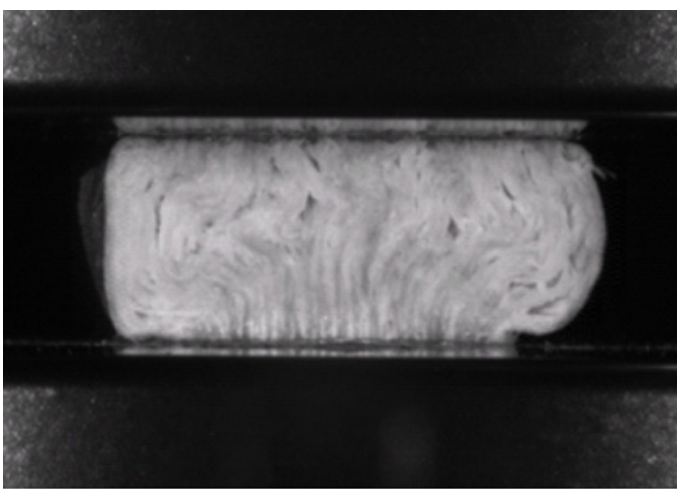

Fig. 23. Compression extended, ply buckling.

Friction coefficient sensitivity is observed and can make switch from a failure mode to another: for example the top can slide on one side or have no perceptible movement resulting in slightly different deformed shape but comparable crush energy.

Model shows a good correlation with experiment for both modulus and failure strain staying within a $15 \%$ error range (Fig. 21 and 22) we find acceptable for crash test. However post failure behaviour show too high stress for $0^{\circ}$ specimen $(40 \%$ error range). 


\section{Conclusions}

This work is promising concerning future simulation of cars crash absorbers. We showed our model is already working on structure showing complex behaviour like the cube during crushing and that we are able to identify it on a reasonable amount of testing data. The actual model handle fracture within the ply very roughly and the model has to be checked and eventually improved on this point. The computational cost remains small for a full 3D model as it is able to run on a desktop computer in a few hours (depending directly on loading speed). The next step will be to compute larger structure. This should be possible thanks to the parallelizable mathematical structure of explicit formulation. Some points remain to be investigated. For now there are distortions problems when going further into the compression calculation. A simpler law (pure elastic/plastic with isotropic hardening) allow to go beyond this point with a good visual correlation (Fig. 23-24) so a solution has to be find for our current model, and handling correctly element deletion seem to be the key.

Model validity after failure and identifications methods have to be improved. Recently delaminating elements calibration is done by an invert method on compression results with a validity check in traction but an alternate way to measure those parameters is needed and we are investigating using a double cantilever beam fixture or a flexion system [1]. Finally I would like to sincerely thank Franck Pasco and Pierrick Guegan for the energy invested in this work and for sharing their skills in instrumentation and mechanical testing in general.

\section{References}

1. S. M. Alkahtani, Z. Y. Zhang, M. O. W. Richardson, Instrumented falling weight impact testing and damage evaluation of Glass/Polypropylene Twintex Composites. Portsmouth University, Portsmouth, Hampshire PO1 3DJ, UK (2005).

2. B. Bonnet, "Comportement au choc de matériaux composites pour applications automobiles" $\mathrm{PhD}$ Ecole Nationale Supérieure des Mines de Paris (2005).

3. Rosen BW. Mechanics of composite strengthening. Fiber composites materials. Metals Park $(\mathrm{OH})$ : American Society of Metals. p. 33-75 (1965).

4. Tsai J, Sun CT. Dynamic compressive strengths of polymeric composites. Int J Solids Struct 41(1112):3211-24 (2004).

5. Q. Bing, C.T. Sun. Modeling and testing strain rate-dependent compressive strength of carbon/epoxy composites Composites Science and Technology 65 2481-2491 (2005).

6. Ninan L, Tsai J, Sun CT. Use of split Hopkinson pressure bar for testing off-axis composites. Int $\mathrm{J}$ Impact Eng. 25:291-313 (2001).

7. S. Marguet, P. Rozycki, L. Gornet, A rate dependent constitutive model for glass-fibre/epoxy-matrix woven fabrics (2006) Computers, Materials and Continua, 4(3):119-135.

8. Marcus Schoßig, Christian Biero, Wolfgang Grellmann and Thomas Mecklenburg. Mechanical behavior of glass-fiber reinforced thermoplastic materials under high strain rates. Polymer Testing 27 (2008) 893-900.

9. P. Ladevèze, O. Allix, J.-F Deü, and D. Lévêque, Mesomodel for localisation and damage computation in laminates (2000) Computer Methods in Applied Mechanics and Engineering, 183(1):105-122.

10. J. Simo, Hugues, T. Computational Inelasticity. Springer (1998).

11. A. Johnson, A. Pickett and P. Rozycki, Computational methods for predicting impact damage in composite structures (2001). 